Viso - Cadernos de estética aplicada Revista eletrônica de estética

ISSN 1981-4062

No 22, jan-jun/2018

http://www.revistaviso.com.br/
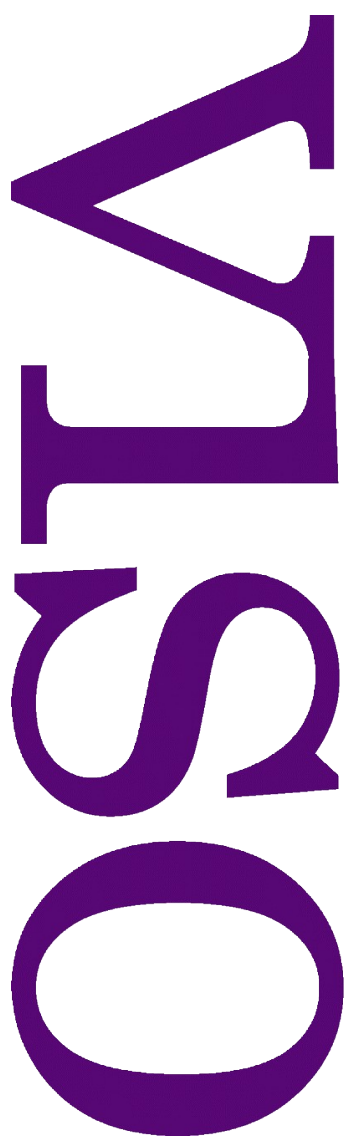

\title{
Performance e presentificação: sobre a forma artística/estética no instante \\ Mariana Lage
}




\section{RESUMO}

Performance e presentificação: sobre a forma artística/estética no instante O artigo propõe pensar e problematizar características e implicações de uma estética do performativo a partir dos trabalhos de Erika Fischer-Lichte e Paul Zumthor, se debruçando, em especial, sobre a duração situacional da performance como poética artística e a evanescência de sua forma artística-estética, a qual se apresenta como contexto-dependente e contingente ao encontro com o público presente. Também levanta questões sobre a percepção da performance e sua presentificação, para, por fim, tecer comentários sobre crítica de arte de performances artísticas.

Palavras-chave: performance - arte contemporânea - forma - crítica - Zumthor

\section{ABSTRACT}

Performance and Presentification: On the Artistic/Aesthetics Form in an Instant

This article intends to think and to problematize some characteristics and implications of a performative aesthetics, having Erika Fischer-Lichte's and Paul Zumthor's works as its background, and focusing in particular on the situational duration of performance as artistic poetics and the evanescence of its artistic-aesthetics form, which presents itself as context-dependent and contingent on the encounter with the present public. It also raises questions about the perception of performance and its presentification, to, afterwards, make comments about performances' art criticism.

Keywords: performance - contemporary art - form - critics - Zumthor 
LAGE, M. "Performance e presentificação: sobre a forma artística/estética no instante". In: Viso: Cadernos de estética aplicada, v. XII, n. 22 (jan-jun/2018), pp. 132-145.

\section{DOI: $10.22409 / 1981-4062 / v 22 i / 243$}

Aprovado: 20.04.2018. Publicado: 30.06.2018.

(c) 2018 Mariana Lage. Esse documento é distribuído nos termos da licença Creative Commons Atribuição-NãoComercial 4.0 Internacional (CC-BY-NC), que permite, exceto para fins comerciais, copiar e redistribuir o material em qualquer formato ou meio, bem como remixá-lo, transformá-lo ou criar a partir dele, desde que seja dado o devido crédito e indicada a licença sob a qual ele foi originalmente publicado.

Licença: http://creativecommons.org/licenses/by-nc/4.0/deed.pt_BR

Accepted: 20.04.2018. Published: 30.06.2018.

(C) 2018 Mariana Lage. This document is distributed under the terms of a Creative Commons Attribution-NonCommercial 4.0 International license (CC-BY-NC) which allows, except for commercial purposes, to copy and redistribute the material in any medium or format and to remix, transform, and build upon the material, provided the original work is properly cited and states its license.

License: http://creativecommons.org/licenses/by-nc/4.0/ 
Desde pelo menos a década de 1950, "performance" tem sido um termo utilizado conceitualmente para referir a diferentes abordagens de pesquisas e a diferentes práticas humanas. Linguística, antropologia, etnografia, sociologia, filosofia da linguagem, artes plásticas e cênicas utilizam-no para referenciar atos de fala, competência comunicativa, comportamento restaurado, folclore, ação social, habilidade técnica, acontecimento artístico, teatralidade, entre outros - a lista de aplicações não pára. ${ }^{1}$ Se não todas, a maior parte dessas abordagens entende performance como ação, ou execução, que dá forma.

O recorte do termo apresentado neste artigo vem da performance como poética artística contemporânea e como conceito nas pesquisas de Paul Zumthor em torno da poesia oral. Advindo das pesquisas etnográficas, o conceito apropriado por Zumthor pode ser utilizado em pesquisas na estética e arte contemporânea como modo de pensar a dinamicidade da experiência estética ou, nas palavras do autor, da percepção poética. Nessa direção, alinhando Zumthor e Erika Fischer-Lichte, podemos encontrar uma perspectiva teórica que privilegia a circunstância e a presentificação, isto é, a dinâmica de uma poética que obtém forma (estética e artística) em copresenças de atoresperformers e público numa situação específica espaço-temporal. Na perspectiva desses autores, chama a atenção a compreensão da obra como ação e acontecimento, de uma temporalidade específica, que envolve performers e público como sujeitos coagentes. Fischer-Lichte nomeia essa abordagem como estética do performativo.

Desta forma, interessa refletir aqui sobre duas principais características dessa estética do performativo: a evanescência da forma artística-estética e sua temporalidade situacional. De forma resumida, Ficher-Lichte e Zumthor entendem a performance como a ação que dá a forma da obra e da percepção estética. Por ser uma ação em curso, limitada a um tempo e espaço circunstancial, pressupondo a presença de outros agentes, denominado público, a performance, como conceito e como poética artística, destaca assim o caráter provisório e contexto-dependente da forma e da percepção estéticas. Essa proposta levanta questões adicionais à estética, diante da necessidade de reconsiderar - e muitas vezes ultrapassar - parâmetros dicotômicos como autor e público, sujeito e objeto, obra e recepção, interpretação e experiência estética, significado e significante etc.

A seguir, portanto, destaco alguns elementos da perspectiva desses autores, dando ênfase ao instante da relação e da percepção como momento privilegiado em que a obra se faz como acontecimento. Em seguida, faço considerações sobre performance e presentificação, para, por fim, fechar o artigo tecendo reflexões sobre crítica e escrita a partir de ou sobre performance artística. 


\section{Estética performativa em Fischer-Lichte}

Em The Transformative Power of Performance, Erika Fischer-Lichte elenca uma série de características de obras que fomentam o que ela chama de estética do performativo. Entendendo a performance como linguagem artística feita de exceções, bastante variável e muitas vezes inapreensível e contraditória, a enumeração oferecida a seguir serve para sintetizar e encontrar elementos basilares que estariam presentes em grande parte de suas manifestações. Algumas dessas características, também elencadas por FischerLichte para qualificar o performativo, são: (i) o artista produz a obra não como artefatos objetais, transferíveis e existentes independentemente do corpo do artista, mas, antes, as obras são concebidas como ações, a serem executadas, vividas e percebidas em copresenças com uma temporalidade específica; (ii) as ações não são representacionais como, por exemplo, no teatro e nas artes cênicas; não há personagens, drama e enredo; (iii) tampouco são concebidas como uma narrativa com início, meio e fim, com um plano a ser executado e/ou ensaiado; (iv) o público é inserido/envolvido na circunstância da ação como agente participante, testemunha, cúmplice ou voyeur, sua presença física é pressuposta como elemento estrutural no fazer do performer; (v) a ação colocada em curso em performance não é feita para ser compreendida por meio de distanciamento reflexivo e interpretação, mas, antes, trata-se de uma experiência a ser vivida (a ponto de muitos autores falarem aqui em rito, como é o caso de Richard Schechner e Victor Turner ${ }^{2}$ ); (vi) em performance, há a simultaneidade temporal e situacional entre o fazer artístico do performer, a apresentação, a obra acontecendo e a percepção do público; (vii) a obra tem a temporalidade de sua duração como acontecimento, ela se torna obra no mesmo instante em que desaparece; (viii) a percepção do público, sua presença e sua participação frequentemente geram uma situação de autopoietic feedback loop, isto é, uma retroalimentação das ações do performer a partir das respostas do público presente, o que determina invariavelmente a forma artística-estética da performance, colocando-a num estado de contingência. Por causa de uma série de elementos como essa, Fischer-Lichte defende que performances frequentemente colocam em estado de tensa oscilação pares dicotômicos como sujeito e objeto, artista e público, obra e recepção, significante e significado, ficção e realidade. Essa tensa oscilação, que ela examina ao longo do livro, comprovaria a importância de se pensar a performance e as artes da ação para além do paradigma da estética da representação - argumento que sustenta as investigações do seu livro em torno de uma estética performativa. ${ }^{3}$

Nesse sentido, enfatiza Fischer-Lichte, as categorias de produção, obra e recepção parecem questionáveis e até obsoletas, visto que a obra se dá em acontecimento dependente da presença atuante e espacialmente simultânea de performer e público. Estaríamos, assim, diante de uma abertura radical da obra, visto que, à disposição do público, ela pode ser redirecionada, reconfigurada ou, inclusive, finalizada de um modo diferente do imaginado ou intencionado pelo artista-performer antes da ação performativa começar. É preciso dizer que, apesar de nos referirmos a elas como instâncias separadas, em performances performer e público se tornam permeáveis e 
interdependentes. Contingência, abertura, transformação, negociações constantes e processos imprevisíveis fazem parte da forma estética e artística da obra em performance. Isso acontece porque um dos elementos de destaque nessa abordagem é o que mencionamos como "autopoietic feedback loop", isto é, o fato de que, em performance, as ações dos performers estão vulneráveis e porosas à presença atuante e participativa do público, e que essa presença contribui diretamente para a forma que a performance adquire ao longo de sua realização. Vale notar que mesmo que o público permaneça indiferente, essa falta de resposta altera o curso de ações do performer. Portanto, o termo autopoietic feedback loop refere-se a uma relação recíproca e interdependente entre performer e público que transforma cada performance em um acontecimento único e irrepetível. Assim, ainda que constituída de uma ação simples, cada performance será única em sua realização e jamais idêntica às suas reperformances.

Cabe mencionar um exemplo para tornar a elaboração teórica mais ilustrativa. Em junho de 2014, a artista Ana Luisa Santos realizou a ação Melindrosa nas imediações da Praça Sete, no hipercentro em Belo Horizonte. A performance teve a duração de cerca de 15 minutos. Nesse período, vemos Ana aparecer vestida com uma roupa composta de notas de dez reais, cujo formato e caimento lembrava as vestimentas da persona que dá nome à performance. Ana está sozinha e em torno dela aos poucos, de forma gradativa, formase um círculo de pessoas curiosas que conversam, interagem, fazem perguntas, na maior parte das vezes, interessados em pegar algumas das notas que compõem a sua roupa. Para cada um que faz a investida de forma verbal ou física, a performer responde de modo semelhante: "você vai me deixar sem roupa?". A tensão entre o público e a performer aumenta com o passar dos minutos, a quantidade de pessoas aglomeradas intensifica e o círculo vai se fechando, até que entre as pessoas presentes e a performer haja cada vez menos espaço e menos saídas. O ponto alto de tensão é alcançado quando duas pessoas retiram algumas notas e saem rapidamente do círculo. O que dá início ao momento seguinte em que estamos em meio a um tumulto e vemos a performer ser jogada de um lado para outro enquanto as pessoas presentes disputam as notas de dez reais. Em questão de segundos, a performance se desfaz. E temos diante de nós uma artista nua, com pouquíssimas pessoas por perto.

Essa mesma performance foi refeita na cidade do Rio de Janeiro, no Largo da Carioca, em novembro de 2017. Nessa ação, vemos o círculo de pessoas se formar mais rápido. Sequer há tempo de a tensão aumentar entre aqueles que querem pegar as notas de dinheiro vivo. Sequer há tempo para que haja um diálogo em que a performer possa questionar o ato do público de lhe arrancar a roupa. Sequer há tempo para que o círculo agregue muitas pessoas. Em dois breves minutos, a performance desaparece.

Nesse breve exemplo de uma dinâmica poética, percebe-se que a obra é constituída de uma ação simples num espaço público aberto à intervenção - e mesmo dependente da interação - do público. Uma mesma obra, dois resultados distintos, enquanto forma 
artística e como percepção estética. Vale ainda dizer que, embora ambas as performances tenham sido registradas em vídeo, a tensão sentida presencialmente é distinta da experiência de assistir aos registros. A tensão é maior diante da contingência de estar fisicamente presente numa situação e não ter uma previsão de o que, ou quando, vai acontecer. Apesar da previsibilidade do resultado final, pode-se dizer que são a tensão entre as negociações constantes da performer com público e a tensão entre a iminência e a ação concreta de tirar as notas que dão conformação à performance - que dão forma à obra, em circunstâncias distintas. Quando vai acontecer a retirada completa da roupa composta por dinheiro e o modo como vai acontecer alimenta a tensão presencial de tomar parte ou ser testemunha.

Nesse sentido, vale destacar aqui a semelhança da abordagem de Fischer-Lichte com a de Zumthor na tentativa de pensar uma estética do performativo. Tendo em vista que é dependente do contexto presente de sua realização, dependente, sobretudo, da presença de quem se encontra no momento de seu acontecimento, a performance se mostra como algo que adquire forma de modo evanescente e incontrolável. Sua forma artística e estética é aquela do instante de sua presentificação. Como demonstram as pesquisas de Peggy Phelan ${ }^{4}$, qualquer movimento com intuito de estabilizar a forma de uma performance, ou mesmo reproduzi-la, transforma-se num ato de documentação e estagnação de algo vivo e movente - e performance como documentação é outro ramo de relevância nos estudos da performance. O trabalho de Phelan, que influenciou fortemente os estudos da área, enfatiza que faz parte da própria "ontologia da performance" o seu desaparecimento: somente existe como um instante e no instante de sua realização. "Sem uma cópia, a performance mergulha na visibilidade - em um presente maniacamente carregado - e desaparece na memória, no domínio da invisibilidade e do inconsciente, onde escapa à regulação e ao controle" ${ }^{5} \mathrm{O}$ registro da performance, na forma de relatos e fotografias, por exemplo, é um resíduo, na forma de arquivo e memória. "A aparente tensão entre sua transitoriedade e as tentativas de fixar a performance através de documentação em vídeo, filme, fotografias e em descrições enfatiza de forma ainda mais clara a efemeridade fundamental e a singularidade da performance". ${ }^{6}$

Outra característica basilar no entendimento de Fischer-Lichte sobre a estética do performativo é a dimensão da presença. Por ser sempre uma ação presente, executada, vivida e percebida em copresenças num dado aqui-agora, performances destacam tanto a presença física dos atores e participantes, quanto a presentidade do acontecimento: o fato de que ocorre num instante circunstancial e que é efêmera. Uma performance é tão presente quanto $\mathrm{o}$ instante. Portanto, ela tem uma temporalidade semelhante ao seu acontecer. "Performance é vivida como a realização, apresentação e passagem do presente". ${ }^{7}$

Quando Fischer-Lichte trata da presença como embodied-mind, isto é, como integração corpo e mente, ela defende a ideia do corpo como "organismo vivo, constantemente 
engajado no processo de se tornar, de permanente transformação". ${ }^{8}$ Ela enfatiza esse aspecto para argumentar que, sendo o corpo algo movente, não estável e em permanente processo de tornar-se, artes da ação ou performances não deveriam ser compreendidas como artefatos artísticos, de sentido estável e independente das circunstâncias de sua realização e percepção. Concebida, entendida e vivida como acontecimento, a performance enfatiza a ação permeável à situação e aos agentes presente em um aqui-agora. A forma da performance é a forma contingente, negociável e porosa das relações numa dada situação simultânea de realização e percepção, jamais possível de se reproduzir idêntica a si mesma, dado que as circunstâncias mudam assim como os sujeitos agentes presentes. Nesse ponto, passo à abordagem da perspectiva de Paul Zumthor, por encontrar também nele a ênfase em uma forma movente, que se dá no instante e evanesce.

\section{A forma do instante em Zumthor}

Paul Zumthor foi um medievalista que se dedicou ao estudo da poesia oral medieval e contemporânea. Suas pesquisas se voltaram para a dinamicidade do ato de comunicação poética vocal, o qual pressupõe, para sua realização, a simultaneidade temporal e espacial de recitante e público ouvinte. Ao longo de sua carreira, traçou caminhos para destacar a provisoriedade, a instabilidade e a temporalidade específica da forma poética percebida em performance. Sendo uma ação colocada em curso por meio de gestos, voz, presenças e engajamentos corporais, a poesia vocal varia sua forma de acordo com as circunstâncias de sua enunciação, execução e percepção. Ela é o resultado do engajamento de presenças, da mobilização da atenção e dos sentidos corporais para o acontecimento poético. Ela demanda, como o autor apontou em diversos momentos, "o calor do contato", "os dons de sociabilidade", "a afetividade", o talento para prender a atenção, para improvisar, fazer rir e emocionar, e se estabelece, assim, pela conexão que o performer-poeta desenvolve, a partir da interpelação, com seu público-ouvinte. ${ }^{9}$ Para essa dinamicidade, Zumthor empregou o termo movência, a fim de destacar que a forma da poesia vocal, diferentemente da letra impressa, não se fixa nem se estabiliza. Num de seus livros, tratou a forma como "ao mesmo tempo síntese do disperso e negação do total" ${ }^{10}$, pois, a cada performance, ela se mostra e se configura de um novo modo: provisória, improvável. "A palavra performance contém forma como um prefixo indicando o acabamento e um sufixo de valor dinâmico". ${ }^{11}$ Ela concretiza e/ou atualiza, numa duração experimentada como instante alargado do presente, diversas possibilidades imagináveis para o texto, tido como modelo-matriz a partir do qual a ação comunicacional da poesia vocal acontece e adquire forma. ${ }^{12}$

Salta aos olhos nos escritos de Zumthor o caráter contingente ao encontro aqui agora da forma poética. Esse destaque da provisoriedade e impermanência se fundamenta na compreensão das características da voz, o veículo corporal e sonoro por meio do qual a comunicação poética se realiza. "A voz é nômade, enquanto a escrita é fixa" ${ }^{13}$, escreveu 
num livro em que contrapõe, em diversos aspectos, a leitura do texto impresso à fluidez da poesia oral. Como vocalidade, gesto e performatividade, a poesia oral é mais um desejo de realização do que completude e globalidade de sentido, tendendo mais ao inacabamento e ao nomadismo do que à fixidez ou permanência de algo a ser compreendido e interpretado, alheio às circunstâncias de produção e enunciação. Quando o autor diz que a forma somente existe em performance, ele aponta para essa circunstância específica da comunicação em que a poesia transita entre os momentos coetâneos de produção, transmissão e percepção. Para ele, a performance é o momento privilegiado em que a oralidade está em cena. "Um dinamismo formalizado", uma "formaforça", a performance vocal coloca tudo em causa. ${ }^{14} \mathrm{~A}$ definição do autor para o termo diz que: "Entre o sufixo designando uma ação em curso, mas que jamais será dada por acabada, e o prefixo globalizante, que remete a uma totalidade inacessível, se não inexistente, performance coloca a 'forma', improvável". ${ }^{15}$ Performance, assim, coloca a forma poética sempre por se fazer. Esta seria a sua movência. Uma movência que é contingente a um encontro específico hic et nunc de comunicação poética, isto é, "num campo dêictico particular, jamais exatamente reproduzível, e segundo condições variáveis, dependendo do número e da qualidade dos elementos não linguísticos em jogo". ${ }^{16}$ Como acontecimento vocal, a forma poética existe enquanto se prolonga no espaço e enquanto engaja presenças. Sua contingência às circunstâncias específicas da performance destaca sua evanescência, provisoriedade e instabilidade. Ao longo de seus livros, o autor sublinha essas características ao tomar como material as variações textuais deixadas por trovadores dos séculos IX ao XIII e por compreender que essas variações demonstravam a permeabilidade ao público do acontecimento poético enquanto uma dinâmica de comunicação oral. A partir de um debruçar reiterante sobre essa dinâmica evanescente de uma voz que se direciona a ouvidos e que desaparece no momento de sua enunciação, Zumthor chega à percepção de que para falar de poesia oral é preciso entendê-la como acontecimento e como movência. Entender mais o como do que especificamente o que é comunicado. É nesse momento de sua carreira que ele se apropria do termo performance, advindo das pesquisas etnográficas, em especial a de Dell Hymes ${ }^{17}$, para falar de uma passagem (breakthrough) em que o texto se torna obra poética. Zumthor detalhou com frequência essa distinção entre texto e obra: enquanto 0 primeiro se refere à estrutura linguística vertida sobre um suporte que o preserva, a segunda se refere a "o que é poeticamente comunicado, aqui e agora" ${ }^{18}$, isto é, à dinâmica da comunicação poética. "É na performance que se fixa, pelo tempo de uma audição, o ponto de integração de todos os elementos que constituem a 'obra'; que se cria e recria sua única unidade vivida: a unidade desta presença, manifesta pelo som desta voz". ${ }^{19}$ Num artigo para o congresso Materialidades da comunicação, de 1987, ele retoma as distinções entre texto e obra para enfocar a especificidade da voz como transmissora da forma poética. Ali, ele se concentra sobre o que chama de situação existencial em que um corpo transmite e outro corpo percebe a qualidade poética do que é produzido em copresenças e em engajamentos corporais; situação existencial caracterizada com termos como ligação concreta, imediaticidade, ambiente, elementos 
cinéticos, processos térmicos e químicos, traços como dimensão e contorno, circunstância, peso e sentidos como a visão, a escuta, o olfato e o toque. Enquanto acontecimento vocal, a obra poética somente existe enquanto há presenças simultâneas e engajadas nos atos de transmissão e percepção. "A questão aqui não é representação ou recusa à representação, mas presença. Cada presença provoca uma fissura na ausência que a precede. Essa fissura cria um ritmo numa duração coletiva e na história dos indivíduos". ${ }^{20} \mathrm{~A}$ diferença da performance de poesia vocal em relação a um texto impresso denota, em especial, a dependência da forma estética-poética da primeira em relação ao corpo e às circunstâncias do seu acontecimento, enquanto que a leitura de um livro impresso permite que o texto seja tomado sob quaisquer circunstâncias, que seja manipulado, saltado, recortado, retomado, relido; seu sentido é, sobretudo, independente das circunstâncias corporais e específicas da sua produção e transmissão. "Saímos do presente, escapamos das exigências de uma presença física, às restrições espacio-temporais. A imprensa vai permitir que um livro seja lido em qualquer lugar e a qualquer momento". ${ }^{21}$

Zumthor evidencia ainda que, para a oralidade e a performance, nada seria mais alheio do que uma abordagem preocupada com a estabilização de um sentido autônomo às circunstâncias de sua transmissão e percepção, e, mais ainda, em busca de um sentido também apartado do engajamento do corpo nas ações de produção, transmissão e percepção. "A performance não pode ser outra coisa senão presente". ${ }^{22}$ É o instante incontrolável, fugidio - de uma comunicação face a face. Que essa comunicação seja poética destaca assim um aspecto da forma que se assemelha ao seu veículo: o nomadismo da voz como o estado de permanente tornar-se do próprio corpo. A movência da forma poética se assemelha ao nomadismo da voz que, enquanto acontecimento, não se fixa, é por natureza um espaço de trânsito, de um corpo ao outro, que desaparece no mesmo instante em que se forma. Aqui, vale lembrar Fischer-Lichte quando ela diz que o corpo não conhece estado de ser, mas apenas de tornar-se: um constante vir a ser, transição permanente.

O texto tradicional, em contrapartida, pelo simples fato de que transita pela voz e pelo gesto, só pode ser aberto, numa abertura primária, radical, a ponto de escapar, por lampejos, à linguagem articulada; por isso ele se esquiva à interpretação, pelo menos a toda interpretação globalizante. ${ }^{23}$

Cabe mais uma vez sublinhar a temporalidade específica da performance: 0 instante duracional de sua realização e de sua percepção, uma temporalidade corporalizada. É neste sentido que entendo presentificação: como ato de tornar presente, corporizar, tornar palpável no instante das presenças físicas compartilhadas em determinado tempo e espaço. Em carta à pesquisadora Jerusa Pires Ferreira, Zumthor refere-se à presentificação como ato de comprimir ou sintetizar toda a duração do tempo num instante atual. ${ }^{24}$ Desta forma, presentificação seria apenas um outro termo para dizer sobre a performance. No entanto, enquanto o termo performance coloca a ênfase na ação que executa e dá forma, a presentificação destaca a temporalidade dessa ação e 
da percepção estética/poética como o instante efêmero, fugidio e evanescente, o aquiagora como efeito físico-corporal da arte como acontecimento. Ao mesmo tempo, a presentificação destaca a fisicalidade das presenças compartilhadas, e, a partir dessa copresença, tem-se, por consequência, o elemento da contingência, abordado anteriormente. "Dessas distinções resulta que não se pode falar de performance de forma totalmente unívoca". ${ }^{25}$

\section{Reflexões finais}

Devido ao seu caráter instantâneo e contingente, ou melhor, à sua forma evanescente, incontrolável e irreprodutível, como falar sobre performances, escrever ou abordá-las criticamente? Esse caráter pode revelar um dos motivos pelos quais é tão difícil chegar a um denominador comum em torno dessa poética artística e, diante da ausência, muitos artigos e livros começam por reconhecer sua pluralidade e abrangência - e algumas vezes, diante de tanta pluralidade, decretam a inutilidade ou improdutividade de abordála como objeto de estudo teórico.

Nos começo de 2017 participei como crítica de um atelier aberto de performance chamado "Perfura", que durou cerca de dois meses na galeria de arte GTO do Sesc Palladium, em Belo Horizonte. Durante esse período, reconheci a necessidade de algo que é bastante comum nos livros que têm a performance como objeto de estudo: o fato de que toda análise, se esta é possível, começa com um relato descritivo minucioso da performance - a sequência de ações, a disposição do espaço e/ou da sala, a presença do público nesse espaço, a disposição física do público, a disposição de humor, ou ainda, a tonalidade afetiva do acontecimento: deitado, em pé, relaxado, tenso, angustiado, indignado, apressado, ativamente e verbalmente participante, etc. $\mathrm{O}$ relato torna presente para o leitor, como público ausente, aquilo que se perdeu. $O$ relato, de certa maneira, socializa a forma fugidia da performance, que se deu num encontro, de uma temporalidade e espacialidade específica. Ele torna conhecível aquilo que existiu num instante. Ele traz para a linguagem verbal e escrita um dinamismo corporal, sinestésico, contingente. Mas, é bom destacar, torna conhecível e comunicável não como foi, como se fosse possível dizer de forma unívoca e inequívoca, mas, antes, apenas um modo possível de percebê-la e de dizê-la.

Se, como descreve Fischer-Lichte, "a questão central da performance não é compreendê-la, mas ter uma experiência e lidar com essa experiência, a qual não poderia ser suplantada, antes ou depois, pela reflexão" ${ }^{26}$, fazer crítica de performance implicaria pensar criticamente o próprio conceito de experiência, assim como o de vivência, estabelecendo parâmetros para uma análise que implica o sujeito como agente coparticipante de uma ação performática específica. Se a crítica de obras de arte já pressupôs, durante a época moderna, a estabilidade de sentido e o distanciamento reflexivo como elementos basilares de seu exercício, como pensar a realização de uma 
crítica para um fazer artístico que implica o público em sua própria realização, que se apresenta como ação a ser executada e vivida, e também que se propõe como ação contingente à situação específica de sua realização, em que cada momento de seu acontecimento se dá de uma outra forma, improvável? Nesse sentido, realizar uma crítica de performance pressupõe não somente a implicação ativa do crítico como agente e fisicamente presente, como pressupõe sua experiência estética - do modo como tiver ocorrido, contaminada por tonalidades afetivas suas, da obra e/ou do público presente. Há ainda a questão adicional e não menos importante: como, por que e para que realizar a crítica de algo que jamais se repetirá de forma idêntica? A crítica de performance poderia ser então uma escrita que reflexivamente apresenta e repensa a experiência proporcionada por uma performance? Se assim for, talvez seria o caso da elaborar uma poética da crítica que utilizasse uma performance como ponto de partida para reflexões contemporâneas que ultrapassam a obra, mas que, de certa forma, estão presentes ali de modo incipiente? Como, por exemplo, tomar a performance Melindrosa, de Ana Luisa Santos, para traçar um ensaio crítico sobre as relações humanas no espaço urbano contemporâneo? Se for apenas um relato do que se apresenta, tal crítica seria uma transposição de linguagens, de algo movente, nômade, instável, para um relato escrito com tendência à fixidez; como uma espécie de documento capaz de historicizar ou guardar no tempo porvir um acontecimento evanescente. Esse documento, vale lembrar, por condição própria, perde as qualidades dinâmicas, corporais e palpáveis, isto é, os estímulos e as percepções sensoriais múltiplas do acontecimento performado. Há de se admitir que, mesmo nessa transcrição, ela daria conta de uma faceta do acontecimento, se apresentando, assim, como uma entre muitas possíveis versões/percepções da performance. Nesse sentido, esse documento tem o desafio adicional de guardar - ou retratar? - numa mídia diferente, a escrita, aquilo que se configura como, nas palavras de Zumthor, um nomadismo, uma "forma-força". Uma crítica de uma linguagem artística movente poderia se encontrar então não num texto reflexivo e argumentativo, mas num essencialmente poético, sem pretensão de interpretação universalizável e globalizante? Como abordar criticamente algo que não se apreende como categoria, como sentido ou forma fixa? Ultrapassando o âmbito do mero relato e sem intenção de extrair um sentido estável e permanente, penso que a reflexão sobre uma performance deveria começar por admitir sua especificidade contextual. Em seguida, admitiria que o relato, a experiência e a reflexão crítica seriam um outro momento da ação vivida, apenas uma faceta da performance ocorrida, uma tentativa de apreender o inapreensível, estabilizar o fugidio, ou talvez, tornar memorável um acontecimento estético-artístico que jamais se repetirá, sendo assim uma dentre outras reverberações de uma forma que aconteceu num instante de ação e percepção estéticas, destacando, sobretudo, a coetaneidade dessas instâncias.

Essas e outras perguntas preliminares sobre crítica de performance podem contribuir para evidenciar algumas questões em aberto para a estética, a filosofia e a crítica de arte diante de uma arte que se dá como acontecimento e presentificação, questões inerentes ao que Fischer-Lichte vem propondo como estética do performativo. Esse caminho 
aberto, a ser traçado e investigado, pode se revelar frutífero para o debate contemporâneo da produção e recepção artísticas. Essas questões ainda podem servir para lapidar e apurar estudos avançados em torno das implicações filosóficas da estética performativa. Um caminho a ser percorrido mais vezes pela crítica e pela estética diante de obras evanescentes e fugidias como são muitas das manifestações artísticas contemporâneas.

\section{* Mariana Lage atua como pós-doutoranda no Departamento de Filosofia da UFJF.}

${ }^{1}$ A esse respeito, conferir o abrangente livro de Marvin Carlson sobre o tema. CARLSON, M. Performance: uma introdução crítica. Tradução de Thaïs F. N. Diniz e Maria Antonieta Pereira Belo Horizonte: Ed. UFMG, 2009.

${ }^{2}$ Cf. TURNER, V. From Ritual to Theatre: The Human Seriousness of Play. New York: Performing Arts Journal Publications, 1982; Idem. "Are There Universals of Performance in Myth, Ritual, and Drama?”. In: SCHECHNER, R.; WILLA, A.; TURNER, V. By Means of Performance: Intercultural Studies of Theatre and Ritual. Cambridge (Massachusetts): Cambridge University Press, 1990; SCHECHNER, R. Performance Theory. Routledge: London and New York, 2004.

3 Cf. FISCHER-LICHTE, E. The Transformative Power of Performance: A New Aesthetics. Translated by Saskya Iris Jain. London. New York: Routledge, 2008, pp. 25-26.

${ }^{4}$ PHELAN, P. Unmarked: The Politics of Performance. Routledge: London and New York, 2005.

${ }^{5}$ Ibidem, p. 148. "Without a copy, live performance plunges into visibility - in a maniacally charged present - and disappears into memory, into the realm of invisibility and the unconscious where it eludes regulation and control".

${ }^{6}$ FISCHER-LICHTE, E. Op. cit., p. 75.

7 Ibidem, p. 94.

${ }^{8}$ Ibidem, p. 92.

${ }^{9}$ ZUMTHOR, P. A letra e a voz: a "literatura" medieval. Tradução de Amálio Pinheiro e Jerusa Pires Ferreira. São Paulo: Companhia das Letras, 1993, p. 222.

${ }^{10}$ Idem. Falando da Idade Média. Tradução de Jerusa P. Ferreira. São Paulo: Perspectiva, 2009, p. 94.

${ }^{11}$ Idem. Escritura e nomadismo: entrevistas e ensaios. Tradução de Jerusa Pires Ferreira, Sonia Queiroz. Cotia (SP): Ateliê Editorial, 2005, p. 56.

12 Idem. "Body and Performance". In: GUMBRECHT, H. U.; PFEIFFER, K. L. Materialities of Communication. Translated by William Whobrey. Stanford: Stanford University Press, 1994, p. 218.

${ }^{13}$ Idem. Escritura e nomadismo: entrevistas e ensaios. Op. cit., p. 52.

${ }^{14}$ Cf. ZUMTHOR, P. Performance, recepção, leitura. Tradução Jerusa Pires Ferreira. São Paulo: Cosac Naify, 2007, p. 29.

15 Ibidem, p. 33.

${ }^{16}$ ZUMTHOR, P. A letra e a voz. Op. cit., p. 219.

17 HYMES, D. "Breakthrough into Performance". In: BEN-AMOS, D; GOLDSTEIN, K. S. (orgs.) Folklore: Performance and Communication. Paris: The Hauge Mouton, 1975. 
${ }^{18}$ ZUMTHOR, P. A letra e a voz. Op. cit., pp. 219-220.

19 Ibidem, p. 163.

${ }^{20}$ ZUMTHOR, P. "Body and Performance". Op. cit., p. 223. "The point here is not representation or the refusal to represent but presence. Every presence provokes a break with the preceding absence. This break creates a special rhythm in collective duration and in the history of individuals".

${ }^{21}$ ZUMTHOR, P. Escritura e nomadismo: entrevistas e ensaios. Op. cit., p. 109.

22 Ibidem, p. 83.

${ }^{23}$ ZUMTHOR, P; A letra e a voz. Op. cit., pp. 283-284.

${ }^{24}$ Cf. FERREIRA, J. P. "Paul Zumthor: Profissão medievalista". In: Revista Signum, n. 1 (nov. 1999), pp. 185-205, aqui p. 191.

${ }^{25}$ ZUMTHOR, P. Escritura e nomadismo: entrevistas e ensaios. Op. cit., pp. 142-143.

${ }^{26}$ FISCHER-LICHTE, E. Op. cit., pp. 16-17. 